\title{
Early to bed and early to rise: Does it matter?
}

\begin{abstract}
Background: Controversy remains about whether early to bed and early to rise makes a man healthy, wealthy and wise (the Ben Franklin hypothesis), or healthy, wealthy and dead (the James Thurber hypothesis).

Methods: As part of the Determinants of Myocardial Infarction Onset Study, we determined through personal interviews the bedtimes and wake times of 949 men admitted to hospital with acute myocardial infarction. Participants reported their educational attainment and zip code of residence, from which local median income was estimated. We followed participants for mortality for a mean of 3.7 years. We defined early-to-bed and early-to-rise respectively as a bedtime before $11 \mathrm{pm}$ and wake time before 6:30 am.
\end{abstract}

Results: Hours in bed were inversely associated with number of cups of coffee consumed (age-adjusted Spearman correlation coefficient $r-0.07, p=0.03$ ). The mortality of early-to-bed, early-to-risers did not differ significantly from other groups. There was also no relation between bed habits and local income, nor with educational attainment.

Interpretation: Our results refute both the Franklin and Thurber hypotheses. Early to bed and early to rise is not associated with health, wealth or wisdom.

S leep medicine, which has a distinguished history dating back to ancient Greece, ${ }^{1,2}$ can be traced in the United States back to Benjamin Franklin, who postulated that "early to bed and early to rise makes a man healthy, wealthy, and wise." ${ }^{3}$ While this hypothesis has readily drifted into the national consciousness, it has been a source of controversy for some time. In fact, James Thurber posited virtually the opposite hypothesis: "early to bed and early to rise makes a male healthy and wealthy and dead." "To date, these competing hypotheses have received surprisingly little attention. Although Chinese adults have been noted to adhere to Franklinesque sleeping hours, ${ }^{5}$ this contrasts with their middling longevity, estimated at 8ist among I9I nations. ${ }^{6}$ Gale and Martyn found no clear difference between "larks and owls" in a follow-up study of I229 British adults, but they inexplicably included both men and women, despite the clear gender-specificity of Franklin's and Thurber's hypotheses.

To test the veracity of the Franklin-Thurber hypotheses, we examined sleep habits among men enrolled in the Determinants of Myocardial Infarction Onset Study (the Onset Study), ${ }^{8,9}$ an inception cohort study of patients admitted to hospital with confirmed acute myocardial infarction (AMI).

\section{Methods}

The Onset Study was conducted in 45 community and tertiary care medical centres in the US. Between I989 and I994, I935

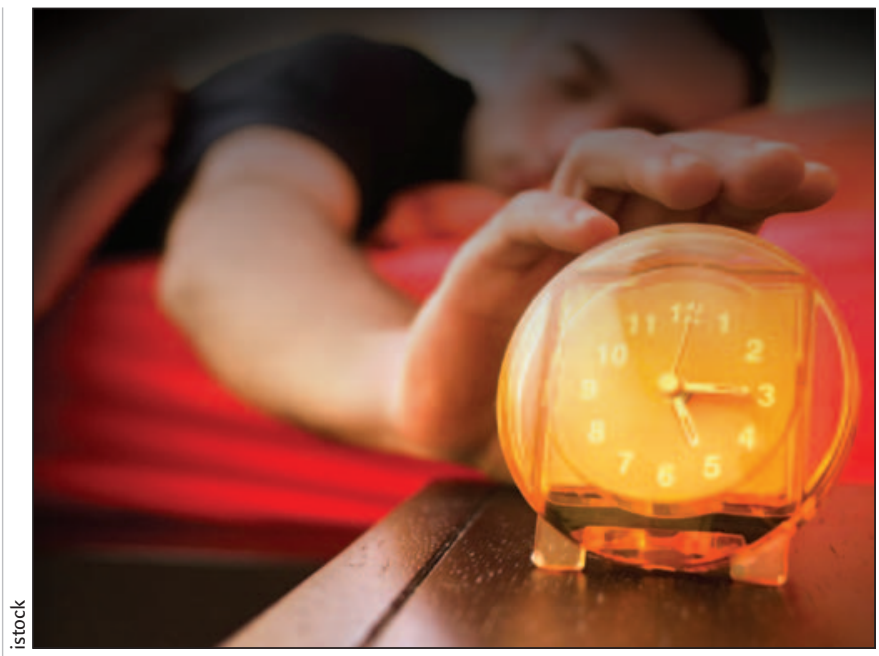

patients (6or women and 1334 men) were interviewed a median of 4 days after sustaining an AMI. For inclusion, patients were required to have a creatine kinase level above the upper limit of normal for each centre, positive MB isoenzymes, an identifiable onset of symptoms of AMI and the ability to complete a structured interview. For these analyses, we excluded 445 participants due to incomplete information on sleep and wake times. To avoid confounding by night shift labour, we also excluded 87 participants with wake times earlier than 4 am or later than noon, or bedtimes earlier than $6 \mathrm{pm}$ or later than $4 \mathrm{am}$. Of the remaining 1403 participants, the 949 men were the focus of our analyses. The institutional review board of each centre approved this protocol, and each participant gave informed consent.

Trained interviewers used a structured data abstraction and questionnaire form that queried participants on a range of characteristics potentially associated with AMI, including age, sex, ethnic origin, education, marital status, medical history, use of caffeine, alcohol and cigarettes, and medication use (both prescription and nonprescription).

Sleep habits were assessed with specific questions regarding the timing of onset of AMI symptoms. Participants reported their usual weekday wake time. As a measure of usual bedtime, participants reported the time that they went to bed and the time that they fell asleep on the last night before the onset of any cardiac symptoms. To test the Franklin-Thurber hypotheses directly, bedtimes, rather than sleep times, were used. Based upon the distributions of bedtimes and wake times in the Onset Study population, we considered participants who reported a bedtime earlier than II pm to be early to bed, and those who reported a usual wake time earlier than 6:30 am to be early to rise.

To estimate wisdom, we asked patients to report their educational attainment in years of schooling. In addition to formal schooling, we included years of education spent in apprenticeships or dedicated technical programs leading to 
certification or licensure (e.g., radio communications or judicial stenography). We subsequently grouped education as less than high school, completion of high school (or the equivalent) and some college, as in previous work. ${ }^{10}$ As a measure of wealth, we used I9go US census data to derive median household income from US Postal Service zip codes.

We searched the National Death Index for deaths of Onset Study participants through I995 and requested death certificates from state offices of vital records for all probable matches, using a previously validated algorithm. ${ }^{11}$ Three physicians independently verified the determination of each death. Disagreements among raters were resolved by discussion.

We tested contingency tables with $\chi^{2}$ tests and means with analysis of variance. In age-adjusted models, we regressed indicator variables for early-late, late-early, and late-late bed and wake times against outcomes of total mortality (in Cox proportional-hazards models), income (in linear regression models) and education (in ordinal logistic regression models). The proportional hazards assumption was found to be satisfied with use of time-varying covariates. ${ }^{12}$ The score test was used to confirm the proportional odds assumption of the ordinal logistic model. No research funding was used; the authors keep sleeping through grant deadlines.

\section{Results}

\section{Patient characteristics}

Table I shows the characteristics of male Onset Study participants according to bed and wake habits. Early risers tended to be younger than late risers. Hours in bed were similar among those whose bedtimes and wake times were both early or both late. Hours in bed were inversely associated with usual number of cups of coffee consumed (age-adjusted Spearman correlation coefficient $r-0.07, p=0.03$ ). Although men who were early to bed and early to rise were most likely to be married (an ambiguous measure of wisdom), this difference was not significant $(p=0.32)$.

\section{Healthy}

A total of 152 men died during a median of 3.7 years of follow-up. Table 2 shows the relation of sleep habits to total mortality. No sleeping pattern differed significantly from the mortality of early-to-bed, early-to-risers. Additional adjustment for marital status did not affect these results, although married men had substantially lower age-adjusted mortality than unmarried men (hazard ratio 0.6 , 95\% confidence interval $0.4-0.8$ ), suggesting that marriage may be a useful measure of wisdom after all. The mortality difference between early and late wake times among participants who went late to bed was of borderline significance $(p=0.04)$.

\section{Wealthy}

Table 2 shows the relation of sleep habits to income, estimated as the median income by zip code of residence. There was no relation evident in age-adjusted analyses.

\section{Wise}

Lastly, Table 2 shows the relation of sleep habits to educational attainment. Individuals who were early to bed and rose late (i.e., the slackers) tended to have the lowest educational attainment (mean difference relative to early-to-bed and earlyto-rise -0.7 years, $95 \%$ confidence interval -0.03 to $-\mathrm{I} .4$ ), but the other groups did not differ significantly from the early-tobed and early-to-rise group.

\section{Interpretation}

Our results do not support the parallel Franklin and Thurber hypotheses that the timing of sleeping or awakening influence health, wealth or wisdom among men, whether positively or negatively. The Franklin hypothesis argues that individuals who enter their beds for sleep and awaken earliest have multiple health and material advantages. It should be noted that Franklin, a polymath but nevertheless a successful politician, had no formal medical training yet remarkable clinical intuition. In the year following exposition of his sleep hypothesis,
Table 1: Characteristics of 949 male Onset Study participants according to bed and rise times

\begin{tabular}{|c|c|c|c|c|}
\hline Characteristic & $\begin{array}{l}\text { Early to bed, } \\
\text { early to rise } \\
\quad n=254\end{array}$ & $\begin{array}{c}\text { Early to bed, } \\
\text { late to rise } \\
n=181\end{array}$ & $\begin{array}{l}\text { Late to bed, } \\
\text { early to rise } \\
\quad n=185\end{array}$ & $\begin{array}{c}\text { Late to bed, } \\
\text { late to rise } \\
n=329\end{array}$ \\
\hline $\begin{array}{l}\text { Mean age } \\
\text { (and SD), yr }\end{array}$ & $58.0(11.4)$ & $64.5(12.3)$ & $56.3(12.3)$ & $60.2(12.5)$ \\
\hline $\begin{array}{l}\text { Mean time in bed } \\
\text { (and SD), } h\end{array}$ & $7.8(1.0)$ & $9.5(1.1)$ & $5.8(1.1)$ & $7.8(1.4)$ \\
\hline White, no. (and \%) & $228(90)$ & $169(93)$ & $169(91)$ & $298(91)$ \\
\hline $\begin{array}{l}\text { Mean body mass } \\
\text { index (and SD), } \\
\mathrm{kg} / \mathrm{m}^{2}\end{array}$ & $27.5(4.9)$ & $26.5(4.4)$ & $28.2(5.3)$ & $27.5(4.8)$ \\
\hline $\begin{array}{l}\text { Married, } \\
\text { no. (and \%)* }\end{array}$ & $204(81)$ & $138(77)$ & $138(75)$ & $241(75)$ \\
\hline $\begin{array}{l}\text { Current cigarette } \\
\text { smoker, } \\
\text { no. (and \%) }\end{array}$ & $88(35)$ & $40(22)$ & $79(43)$ & $99(30)$ \\
\hline $\begin{array}{l}\text { Mean weekly } \\
\text { coffee intake } \\
\text { (and SD), cups }\end{array}$ & $18(18)$ & $15(30)$ & $25(34)$ & $18(24)$ \\
\hline
\end{tabular}

Note: Mean values and standard deviations (SD) are shown for continuous variables. Counts and proportions are shown for categorical variables.

*A small number of data was missing for this question, but the percentages reflect the true proportions among men who provided complete information. 
Table 2: Measures of health, wealth and wisdom among 949 male Onset Study participants according to bed and rise times

\begin{tabular}{|c|c|c|c|c|}
\hline Measure & $\begin{array}{l}\text { Early to bed, } \\
\text { early to rise } \\
\quad n=254\end{array}$ & $\begin{array}{c}\text { Early to bed, } \\
\text { late to rise } \\
\quad n=181\end{array}$ & $\begin{array}{l}\text { Late to bed, } \\
\text { early to rise } \\
\quad n=185\end{array}$ & $\begin{array}{l}\text { Late to bed, } \\
\text { late to rise } \\
n=329\end{array}$ \\
\hline \multicolumn{5}{|l|}{ Health } \\
\hline No. of deaths & 37 & 37 & 17 & 61 \\
\hline Age-adjusted hazard ratio & 1.0 & 0.9 & 0.7 & 1.1 \\
\hline $95 \%$ confidence interval & Reference & $(0.6-1.5)$ & $(0.4-1.2)$ & $(0.7-1.7)$ \\
\hline \multicolumn{5}{|l|}{ Wealth } \\
\hline $\begin{array}{l}\text { Mean annual income } \\
\text { (and SD), \$ }\end{array}$ & $\begin{array}{c}38162 \\
(12 \quad 445)\end{array}$ & $\begin{array}{c}37881 \\
(10480)\end{array}$ & $\begin{array}{c}39438 \\
(13316)\end{array}$ & $\begin{array}{c}39407 \\
(14580)\end{array}$ \\
\hline Age-adjusted differences & 0 & -439 & +1324 & +1188 \\
\hline 95\% confidence interval & Reference & $(-3019$ to 2141$)$ & $(-1193$ to 3840$)$ & (-983 to 3360$)$ \\
\hline \multicolumn{5}{|l|}{ Wisdom } \\
\hline Mean years of schooling (and SD) & $13.1(3.6)$ & $12.2(3.7)$ & $13.1(3.6)$ & $13.2(3.4)$ \\
\hline $\begin{array}{l}\text { Age-adjusted odds ratio for } \\
\text { greater education }\end{array}$ & 1.0 & 0.8 & 1.0 & 1.3 \\
\hline $95 \%$ confidence interval & Reference & $(0.6-1.2)$ & $(0.7-1.5)$ & $(0.9-1.7)$ \\
\hline
\end{tabular}

Franklin noted that "God heals, and the Doctor takes the Fees." In the same year, he also expounded sound nutritional advice regarding both obesity and marine long-chain fattyacid intake: "I saw few die of Hunger, of Eating Ioo ooo" and "Marry your Daughter and eat fresh Fish betimes."

In contrast, Thurber's hypothesis appears to have been driven largely by his own experience. He notes, "I used to wake up at 4 A.M. and start sneezing, sometimes for five hours. I tried to find out what sort of allergy I had but finally came to the conclusion that it must be an allergy to consciousness." However, in other scientific matters, Thurber appears to have possessed insight nearly that of Franklin's. A brief perusal of the medical literature suggests that his advice regarding scientific publication - "Don't get it right, just get it written" — has, alas, gained widespread, if unrecognized, adoption.

We acknowledge several limitations of our work. First, we enrolled a population of AMI patients and, thus, none can truly be considered healthy. However, none of us is really all that healthy anyway. Second, due to our own lack of wisdom, we know of no reliable and validated instruments to measure it; education is but an ill-schooled substitute. Third, we had no measures of personal income, and thus these analyses test the rather oblique hypothesis that earlyto-bed and early-to-rise makes a man's locale of residence wealthy.

In conclusion, we found no evidence to support the Franklin or Thurber hypotheses that sleep habits dictate health, wealth or wisdom, either for the good or the bad. Further research remains necessary to determine whether Franklin's ("He that lives upon Hope, dies farting") or Thurber's ("It is better to have loafed and lost, than never to have loafed at all") other hypotheses fare better under formal scrutiny.

\section{Kenneth J. Mukamal}

Department of Medicine

Beth Israel Deaconess Medical Center

Gregory A. Wellenius

Department of Environmental Health

Murray A. Mittleman

Department of Epidemiology

Harvard School of Public Heath

Department of Medicine

Beth Israel Deaconess Medical Center

Boston, Mass.

This article was peer reviewed by someone. Peggy? You read this, right?

\section{REFERENCES}

I. Kryger MH. Fat, sleep, and Charles Dickens: literary and medical contributions to the understanding of sleep apnea. Clin Chest Med 1985;6:555-62.

2. Michalopoulos A, Tzelepis G, Geroulanos S. Morbid obesity and hypersomnolence in several members of an ancient royal family. Thorax 2003;58:28I-2.

3. Franklin B. Poor Richard's almanack. Philadelphia: B. Franklin and D. Hall; 1735.

4. Thurber JG. The shrike and the chipmunks. New Yorker, I939 Feb I8.

5. Liu X, Liu L. Sleep habits and insomnia in a sample of elderly persons in China. Sleep 2005;28:1579-87.

6. Mathers CD, Sadana R, Salomon JA, et al. Healthy life expectancy in IgI countries, I999. Lancet 200I;357:1685-91.

7. Gale C, Martyn C. Larks and owls and health, wealth, and wisdom. BMJ I998;317:1675-7.

8. Mittleman MA, Maclure M, Tofler GH, et al. Triggering of acute myocardial infarction by heavy physical exertion. Protection against triggering by regular exertion. Determinants of Myocardial Infarction Onset Study Investigators. $N$ Engl J Med 1993;329:1677-83.

9. Mukamal KJ, Muller JE, Maclure M, et al. Evaluation of sex-related differences in survival after hospitalization for acute myocardial infarction. Am J Cardiol 2001;88:768-71.

Io. Mittleman MA, Maclure M, Nachnani M, et al. Educational attainment, anger, and the risk of triggering myocardial infarction onset. The Determinants of Myocardial Infarction Onset Study Investigators. Arch Intern Med I997;157:769-75.

II. Stampfer MJ, Willett WC, Speizer FE, et al. Test of the National Death Index. Am Epidemiol I984;II9:837-9.

I2. Ng'andu NH. An empirical comparison of statistical tests for assessing the proportional hazards assumption of Cox's model. Stat Med I997;16:6II-26. 